\title{
At what depth is the Eemian layer expected to be found at NEEM?
}

\author{
Susanne L. BUCHARDT, Dorthe DAHL-JENSEN \\ Ice and Climate, Niels Bohr Institute, University of Copenhagen, Juliane Maries Vej 30, DK-2100 Copenhagen, Denmark \\ E-mail: lilja@gfy.ku.dk
}

\begin{abstract}
No continuous record from Greenland of the Eemian interglacial period (130-115 ka BP) currently exists. However, a new ice-core drill site has been suggested at $77.449^{\circ} \mathrm{N}, 51.056^{\circ} \mathrm{W}$ in northwest Greenland (North Eemian or NEEM). Radio-echo sounding images and flow model investigations indicate that an undisturbed Eemian record may be obtained at NEEM. In this work, a two-dimensional ice flow model with time-dependent accumulation rate and ice thickness is used to estimate the location of the Eemian layer at the new drill site. The model is used to simulate the ice flow along the ice ridge leading to the drill site. Unknown flow parameters are found through a Monte Carlo analysis of the flow model constrained by observed isochrones in the ice. The results indicate that the Eemian layer is approximately $60 \mathrm{~m}$ thick and that its base is located approximately $100 \mathrm{~m}$ above bedrock.
\end{abstract}

\section{INTRODUCTION}

Ice from the Eemian period (130-115 ka BP) was found in the central Greenland ice cores (GRIP (Greenland Icecore Project) and GISP2 (Greenland Ice Sheet Project 2)) as well as in the NorthGRIP (North Greenland Icecore Project) ice core. The early part of the Eemian layer was, however, gone in the latter due to a high basal melt rate, and in the central Greenland cores the stratigraphy was broken in the bottom $10 \%$ of the cores due to flow over an uneven bed. An undisturbed record of the full Eemian period has therefore not yet been obtained from Greenland. A new ice-core drill site, NEEM (North Eemian), has been suggested at $77.449^{\circ} \mathrm{N}$, $51.056^{\circ} \mathrm{W}$ in northwest Greenland, and drilling is planned to begin in 2008. The NEEM drilling project is an international effort with 14 participating nations, and its main purpose is to retrieve a continuous record of the whole Eemian interglacial.

The new drill site is located $365 \mathrm{~km}$ downstream from NorthGRIP on the ice ridge that runs north-northwest from GRIP via NorthGRIP towards Camp Century (see Fig. 1). The

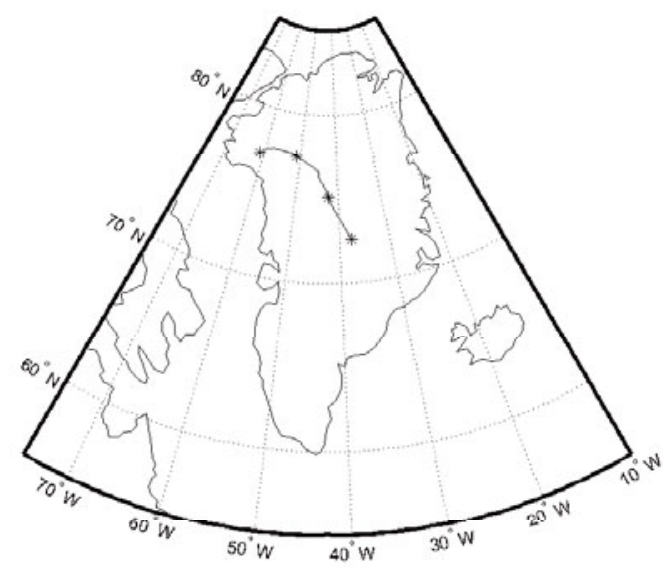

Fig. 1. Map of Greenland with indicated drill sites along the ice ridge in northwest Greenland. Starting from the south and moving along the flowline the drill sites are: GRIP, NorthGRIP, NEEM and Camp Century. altitude at NEEM is $2447 \mathrm{~m}$ and radar investigations indicate an ice thickness of $2561 \mathrm{~m}$. The accumulation rate and surface velocity are not well known but they are expected to be somewhat larger than at NorthGRIP since NEEM is located further out on the flank at lower altitude and with steeper surface slope. From radio-echo sounding (RES) images it is seen that the very smooth bed found around NorthGRIP does not extend all the way to the NEEM drill site. However, the bedrock undulations at NEEM are on a much smaller scale than at GRIP, so there is no immediate reason to suspect folding of the deep layers. The location of the drill site for the new ice core was selected from studies of the internal structure of the ice, as seen on RES images. The Eemian layer is located too deep in the ice to show up in the existing RES images, but the shape of the younger internal layers indicates that Eemian ice is located relatively high above the bed at NEEM. A modelling effort is needed in order to predict the depth and thickness of the Eemian layer.

\section{RADAR DATA}

Large parts of the Greenland ice sheet have been investigated with airborne radio-echo sounders by the Center for Remote Sensing of Ice Sheets, University of Kansas, USA (Chuah and others, 1996). The RES images show the ice surface, the icebedrock interface and internal layers in the ice. Individual internal layers can be followed over hundreds of kilometres and are generally accepted as isochrones. The shape of the isochrones reveals information about the ice dynamics, especially the basal melt rate. Undulations which increase with depth are an indication of spatially changing basal melt rates. In an area with a high basal melt rate, the isochrones will be pulled down faster than in areas with low or no basal melting.

In order to constrain a Monte Carlo analysis of the inverse problem presented below, we need a dated set of observed isochrones. Twelve layers have been traced from NorthGRIP to NEEM in the RES images. The layers are dated from their depths in the NorthGRIP ice core, and their ages fall between 3.6 and $79.8 \mathrm{ka}$. The two deepest isochrones are very faint in the RES images, and in some areas they are impossible to trace. However, the visible parts of these two layers are included, as it is crucial to have deep constraints on the Monte Carlo analysis. 


\section{MODELLING}

\section{Forward model}

A $224 \mathrm{~km}$ long section along the north-northwest-trending ice ridge is considered, and a model approach similar to that used by Buchardt and Dahl-Jensen (2007) is taken. The ice flow along the ice ridge is therefore simulated using a two-dimensional Dansgaard-Johnsen model (Dansgaard and Johnsen, 1969) that accounts for basal melting and sliding. The model requires surface velocity $u_{\text {sur, }}$ ice thickness $H$, accumulation rate $a$, basal melt rate $w_{\mathrm{b}}$, kink height $h$ and the ratio of basal sliding velocity to surface velocity $F_{\mathrm{B}}$ as input. The horizontal velocity $u$ and the vertical velocity $w$ are calculated as

$$
u= \begin{cases}u_{\text {sur }} & z \in[h, H] \\ u_{\text {sur }}\left(F_{\mathrm{B}}+\left(1-F_{\mathrm{B}}\right) \frac{z}{h}\right) & z \in[0, h]\end{cases}
$$

and

$w=\left\{\begin{array}{ll}\frac{\partial w_{\text {sur }}}{\partial z}\left(z-\frac{1}{2} h\left(1-F_{B}\right)\right)-w_{\mathrm{b}} & z \in[h, H] \\ \frac{\partial w_{\text {sur }}}{\partial z}\left(F_{\mathrm{B}} Z+\frac{1}{2}\left(1-F_{\mathrm{B}}\right) \frac{z^{2}}{h}\right)-w_{\mathrm{b}} & z \in[0, h]\end{array}\right.$,

where $z$ is the ice equivalent height above bedrock and

$$
\frac{\partial w_{\text {sur }}}{\partial z}=\frac{w_{\mathrm{b}}-a}{H-\frac{1}{2} h\left(1-F_{\mathrm{B}}\right)} \text {. }
$$

All parameters are allowed to vary horizontally, whereas temporal changes are only considered for $H$ and $a$.

The spatial variation in $H$ is known from radar surveys (Chuah and others, 1996), and the temporal changes are calculated using the SICOPOLIS (SImulation COde for POLythermal Ice Sheets) ice-sheet model for Greenland (Greve, 2005). The accumulation rates in the area are not well known. Accumulation rate values along the ice ridge are inferred from Ohmura and Reeh (1991) but tuned to match the known values at the drill sites. The accumulation maps from Ohmura and Reeh (1991) are based on interpolations between measurements with a coarser resolution than optimal for use in this study. We therefore wish to allow for the possibility that the overall pattern with low values in the centre of the ice sheet and higher values closer to the coast is more pronounced in the area of study than suggested by the current dataset. This is done by adding to the data a contribution that grows linearly with the distance from NorthGRIP (where the accumulation rate is well determined). The speed $\gamma$ with which the contribution grows with distance is left to be determined from the Monte Carlo analysis.

The accumulation history is calculated from the dated $\delta^{18} \mathrm{O}$ record from NorthGRIP using a model similar to that developed by Johnsen and others (1995). We therefore have high accumulation in warm periods and low in cold periods. It is assumed that the ratio of the accumulation rate at any point along the line to that at NorthGRIP is constant in time. The oldest ice found in the NorthGRIP ice core has been dated to $123 \mathrm{ka}$. When starting the forward model before this time, the glacial index from Greve (2005) is used to scale the accumulation further back in time.

The surface velocities in the area around NEEM are not known. However, from empirical studies of the area around NorthGRIP where a strain net was established, a linear relationship between surface slope and along-ridge surface velocities has been found. Therefore, the value of $u_{\text {sur }}$ is in this

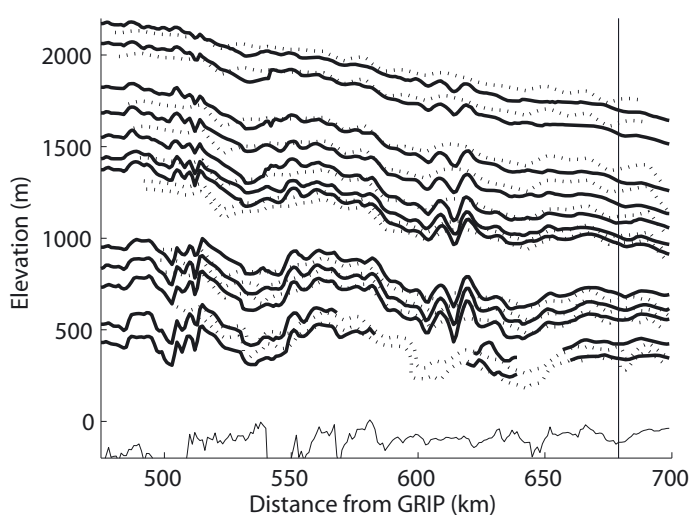

Fig. 2. Observed (solid lines) and modelled (dotted lines) isochrones. The NEEM drill site is indicated by the vertical line.

work calculated as a linear function of the observed surface slope, i.e.

$$
u_{\text {sur }}=C \frac{\mathrm{d} S}{\mathrm{~d} x},
$$

where $C$ is a constant and $d S / d x$ is the surface slope. The value of $C$ is chosen so that the calculated surface velocity at NorthGRIP matches the observed value of $1.3 \mathrm{ma}^{-1}$ (Hvidberg and others, 2002). At all times, the value of $u_{\text {sur }}$ calculated as above is scaled with the factor $a(t) / a_{0}$ to compensate for the changes in accumulation rate.

The value of $w_{\mathrm{b}}$ is allowed to change for every $8 \mathrm{~km}$, giving rise to 28 different unknown values along the section. The kink height $h$ and the fraction of basal sliding $F_{\mathrm{B}}$ are tied linearly to the melt rate to restrict the number of unknowns (Buchardt and Dahl-Jensen, 2007).

To investigate the importance of including the temporal changes of $H$, the model is also run with $\mathrm{d} H / \mathrm{d} t=0$ for comparison.

\section{Solving the inverse problem}

Thirty-four parameters from the forward model are unknown and must be determined from a Monte Carlo analysis. The forward model is run several hundred thousand times with various combinations of values for the model parameters. After each run, the fit between observed isochrones and isochrones calculated by the forward model is used to decide whether the used model parameters should be accepted or rejected. The values of the model parameters are changed between each run by using random numbers (a random walk in the model space). By examining the statistical properties of the accepted values for the model parameters, best estimates for these 34 unknown parameters can be inferred. A more thorough description of the Metropolis algorithm used to solve this problem is given by Buchardt and DahlJensen (2007).

\section{RESULTS AND DISCUSSION Time-dependent ice thickness}

The fit between the observed and the modelled isochrones is satisfactory. The modelled isochrones recreate the overall shape of those observed (Fig. 2). About $50 \mathrm{~km}$ upstream from NEEM, the observed isochrones display high-amplitude undulations. These variations happen over too short a distance 

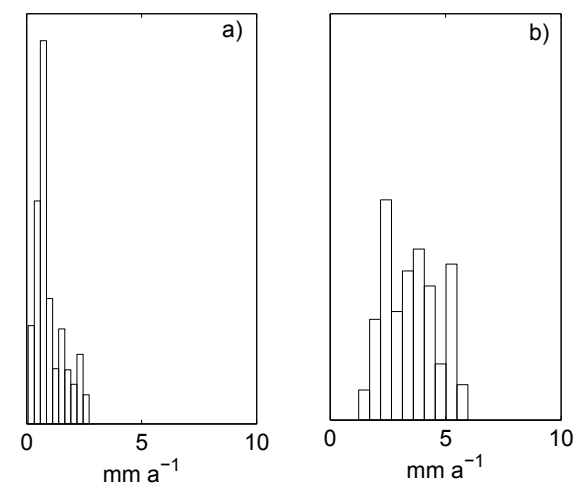

Fig. 3. Histogram of accepted values for the melt rate (a) in the interval at NEEM and (b) $75 \mathrm{~km}$ upstream from NEEM, where there are no data for the lowest two isochrones. In (a), the histogram shows a single maximum, so the melt rate in this interval is well defined by the solution. However, it can be seen that the solution in (b) does not provide a well-defined value for the melt rate.

to be resolved by the model, which has melt rate intervals $8 \mathrm{~km}$ long.

Most model parameters are well defined by the Monte Carlo analysis, i.e. the histograms of the accepted values for the parameters resemble Gaussian distributions. Only the melt rate values in the intervals where there are no data for the two deepest isochrones are not well defined. In these intervals, the distributions for the accepted values for the melt rate are broader and do not show a clear single maximum (Fig. 3). This illustrates the importance of including deep isochrones if information on the melt rate is required.

The melt rate at NEEM is found to be $1.0 \pm 0.6 \mathrm{~mm} \mathrm{a}^{-1}$. However, about $50 \mathrm{~km}$ upstream from the drill site where the observed layers show undulations of a very high amplitude, values of almost $11 \mathrm{~mm} \mathrm{a}^{-1}$ are found. Using the value of $\gamma$ found from the Monte Carlo analysis, we find the accumulation rate at NEEM to be $0.26 \mathrm{ma}^{-1}$.

Running the forward model with the parameter estimates found from this analysis results in a modelled Eemian layer of $60 \pm 10 \mathrm{~m}$ thickness located $100 \pm 40 \mathrm{~m}$ above bedrock at NEEM (Fig. 4). The age of the ice at the base is estimated to be around $200 \mathrm{ka}$. Eemian ice has been transported approximately $50 \mathrm{~km}$ along the ice ridge since deposition. It is therefore not likely that the Eemian layer has been significantly affected by the higher melt rates in the previously mentioned area with large undulations of the isochrones.

\section{Constant ice thickness}

The general observations regarding fit and well-determined parameters for the model with constant ice thickness are the same as for the analysis of the model with time-dependent ice thickness. The thickness of the Eemian layer is found to be $75 \pm 10 \mathrm{~m}$ and the base of the layer is found to be located $150 \pm 40 \mathrm{~m}$ above bedrock. The accumulation rate in this case is found to be $0.27 \mathrm{~m} \mathrm{a}^{-1}$ and the melt rate is $1.0 \pm 0.5 \mathrm{~mm} \mathrm{a}^{-1}$.

In the upper part of the ice sheet, solving both inverse problems results in modelled isochrones that are too shallow close to NEEM and too deep upstream from the drill site (Fig. 2). A possible cause for this is that the accumulation pattern used in the model may not be a good estimate of the true accumulation pattern. Furthermore, changes over

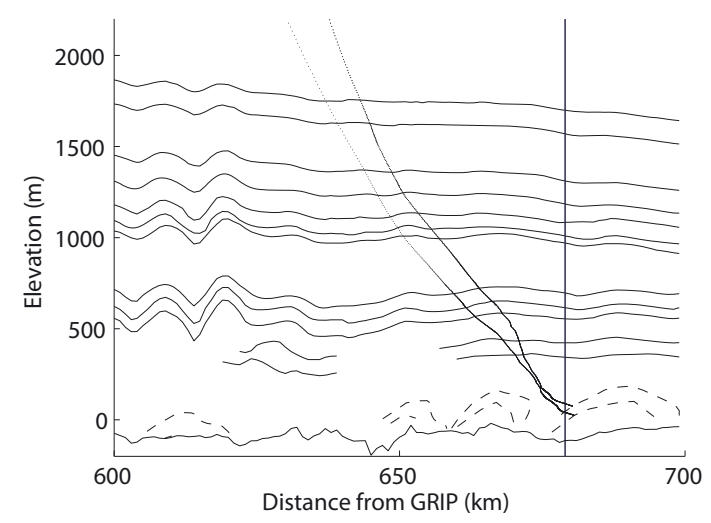

Fig. 4. Observed isochrones (solid lines) and modelled top and base of the Eemian layer (dashed lines) calculated from the model with time-dependent ice thickness. The dotted lines show the paths that the top and the base of the Eemian layer at NEEM have taken through the ice. The NEEM drill site is indicated by the vertical line.

time in the accumulation pattern are not accounted for in the model but may have significantly influenced the shape of the observed isochrones.

\section{CONCLUSION}

Both models indicate that a full record of the Eemian period can be obtained at NEEM, and both models predict the layer to be located well above bedrock. The model with time-dependent ice thickness predicts an Eemian layer of $60 \pm 10 \mathrm{~m}$; the model with constant ice thickness over time predicts a thickness of $75 \pm 10 \mathrm{~m}$. Both solutions indicate basal ice of an age of at least $200 \mathrm{ka}$. The melt rate at NEEM is estimated to be $1 \mathrm{~mm}$ with an uncertainty of around $0.5 \mathrm{~mm}$. This is good news for the drilling project, since a small melt rate keeps the layer thickness at the base larger than if there is no melting.

\section{REFERENCES}

Buchardt, S.L. and D. Dahl-Jensen. 2007. Estimating the basal melt rate at NorthGRIP using a Monte Carlo technique. Ann. Glaciol., 45, 137-142.

Chuah, T.S., S.P. Gogineni, C. Allen and B. Wohletz. 1996. Radar thickness measurements over the northern part of the Greenland ice sheet. Lawrence, KS. University of Kansas Center for Research Inc. Radar Systems and Remote Sensing Laboratory. (Technical Report. 10470-3.)

Dansgaard, W. and S.J. Johnsen. 1969. A flow model and a time scale for the ice core from Camp Century, Greenland. J. Glaciol., 8(53), 215-223.

Greve, R. 2005. Relation of measured basal temperatures and the spatial distribution of the geothermal heat flux for the Greenland ice sheet. Ann. Glaciol., 42, 424-432.

Hvidberg, C.S., K. Keller and N.S. Gundestrup. 2002. Mass balance and ice flow along the north-northwest ridge of the Greenland ice sheet at NorthGRIP. Ann. Glaciol., 35, 521-526.

Johnsen, S.J., D. Dahl-Jensen, W. Dansgaard and N.S. Gundestrup. 1995. Greenland paleotemperatures derived from GRIP borehole temperature and ice core isotope profiles. Tellus $B$, 47(5), 624-629.

Ohmura, A. and N. Reeh. 1991. New precipitation and accumulation maps for Greenland. J. Glaciol., 37(125), 140-148. 